\title{
La radiología digital para relicarios de ceroplástica: estudio interdisciplinar para identificar el sistema constructivo y la ubicación de los restos óseos
}

\author{
Gabriela Sánchez Reyes, José Luis Velázquez Ramírez, Ana Lucía Montes Marrero
}

\begin{abstract}
Poco se han estudiado los relicarios en ceroplástica de origen romano, simulacros de cera y otros materiales que representan el cuerpo de santos catacumbales, denominados corpi santi. En su interior resguardan restos óseos variados, expuestos ya fuera en la cabeza o en las extremidades a través de ventanas, y su técnica de factura es poco conocida. A partir de la radiología digital directa, técnica no invasiva, se propone analizarlos para conocer el sistema constructivo que muestra variantes en cada ejemplar, identificar la cantidad y ubicación exacta de las reliquias, y su estado de conservación general.
\end{abstract}

Keyword: Radiología digital, ceroplástica, relicario, reliquia, cuerpo santo, santo catacumbal, sistema constructivo, técnica de factura, conservación, corpi santi.

\section{The digital radiology for ceroplastic reliquaries: interdisciplinary study to identify the constructive system and the location of the skeletal remains}

Resumen: There are few studies about Roman ceroplastic reliquaries. These sculptures are a kind of wax simulacrum, representing the body of Catacomb saints or "corpi santi". Inside them, some bones are to be found in head, arms or legs, visible through windows. However, their manufacture in unknown. From direct digital radiology, a non-invasive technique, we proposed, to analyze them to know, not only the constructive system. But also, to identify the exact amount and location of the relics inside, and their general state of preservation, since each piece, is different to another.

Palabras clave: direct digital radiology, ceroplastic, reliquary, relic, catacomb saints, construction system, manufacture, conservation, corpi santi.

\section{A radiografia digital para relicários ceroplásticos: estudo interdisciplinar para identificar o sistema construtivo e a localização de restos ósseos}

Resumo: Pouco se tem estudado os relicários ceroplásticos de origem romana, simulacros de cera e outros materiais que representam o corpo de santos catacumbais, denominados corpi santi. No seu interior, protegem-se variados restos ósseos expostos na cabeça ou nas extremidades através de aberturas, sendo pouco conhecidas as suas técnicas de execução. A partir da radiografia digital direta, técnica não-invasiva, propõe-se analizá-los para conhecer o sistema construtivo que mostra variantes em cada exemplar; identificar a quantidade e a localização exata das reliquias e o seu estado geral de conservação.

Palavras-chave: Radiografia digital, ceroplástico, relicario, corpo santo, santo catacumbal, sistema construtivo, técnica de execução, conservação, corpi santi. 


\section{Introducción}

La investigación sobre el origen de las reliquias remite a distintos periodos históricos, el más importante de ellos fue el hallazgo fortuito ocurrido el 31 de mayo de 1578 en la vía Salaria, en un viñedo que pertenecía a Bartolomé Sánchez de Alda, que revelaría un mundo de vestigios de los primeros mártires de la Iglesia Católica, que denominó corpi santi o "cuerpo santo", que define únicamente a un tipo de reliquias mártires extraídas de las catacumbas romanas. Este hecho dio origen a la idea de una nueva Roma subterránea, recinto donde serían buscados con tesón las osamentas sagradas, para ser repartidos por la cristiandad. Este inventio o descubrimiento de reliquias fue duramente criticado por los protestantes, pero para la Iglesia Romana esto no fue sino la confirmación divina del culto a las reliquias y a los santos, por lo que su presencia fue una herramienta para iniciar un proceso de cristianización, no sólo en Europa sino también en América. Los restos óseos de los mártires romanos fueron tan apreciados que surgió un tráfico y venta de falsas reliquias, por lo que en 1667, se creó la Congregación de Indulgencias y de Santas Reliquias, entre cuyas funciones estaba vigilar la extracción y autenticación de cuerpos santos a través del Vicario de Roma. El origen de la arqueología cristiana también fue un fruto de este descubrimiento, que tenía como meta la extracción de mártires para poblar los templos con estos vestigios y testimonios de santidad. Uno de los grandes estudiosos fue Antonio Bosio (1575-1629) que exploró sistemáticamente las catacumbas desde 1593, y sus observaciones serían publicadas, de manera póstuma, en la obra Roma subterránea (Roma sotterranea). En el caso de México, por ejemplo, las reliquias llegaron como resultado del intenso proceso de circulación y traslado de reliquias por el mundo católico; apenas establecidas las órdenes religiosas, comenzaron a formarse colecciones de reliquias que se ostentaban ya fuera en las sacristías, retablos, capillas o en altares domésticos. (Sánchez, en proceso).

El estudio de la reliquia está en relación con el relicario, por ello es necesario estar familiarizado con las tipologías, terreno que aún debe explorarse debido a la gran variedad formal que existe, y del que falta aún profundizar. Su identificación es de gran utilidad para su catalogación, no sólo en museos sino para ingresarlos en bases de datos de registro patrimonial. El relicario debe entenderse como un receptáculo en cuyo interior se resguardan, los restos de los santos. En general puede decirse que tiene dos funciones básicas: proteger su contenido sagrado y a la vez, exponer y dejar visible una parte o la totalidad de la reliquia. Una de las tipologías que han sido analizadas es el relicario de ceroplástica, que no cuenta con una terminología aceptada de manera generalizada. En unos casos lo llaman "imagenrelicario" (Bouza 1990), en otros como "relicarios-estatuas de cera" (Ballestriero 2013), o bien como corpisanti en cerolástica (corpisanti in ceroplástica) (Ghilardi 2015); mientras que la historiografía francesa los designa como corp-reliquiare o cuerpo-relicario (Laurence 1999), es esta última designación la que se ha adoptado porque nos parece es inequívoca, ${ }^{1}$ para designar un cuerpo completo elaborado en cera en cuyo interior se resguardan restos óseos de un mártir catacumbal romano. Estas obras se caracterizan por estar generalmente en posición yacente, tener vestimentas elaboradas con textiles lustrosos, aplicaciones de postizos, accesorios y en ocasiones con una palma del martirio, una tablilla con su nombre y el vas sanguinis o vaso de sangre. Todo lo anterior se encuentra dentro de urnas realizadas especialmente para cada ejemplar. Para su exposición, algunos huesos son visibles gracias a pequeñas ventanas localizadas en los brazos, pecho, piernas, plantas de los pies y palmas de las manos, y en ocasiones en la parte posterior del cráneo, por lo que es importante señalar, que la cantidad de ventanas varía en cada ejemplar. A pesar de haber sido incorporado este tipo de relicario a estudios sobre santos catacumbales (Bouza 1990) o en fechas más recientes como una tipología de obras de ceroplástica (Ballestriero 2013), se desconocen detalles sobre su elaboración, cantidad y ubicación exacta de las reliquias, puesto que sólo se podía realizar una observación superficial de la imagen, sembrando de alguna forma, la incertidumbre respecto al contenido. ${ }^{2}$ (Ghilardi 2015)

En la historiografía de la historia del arte virreinal en México, pocos acercamientos se habían realizado sobre este tipo de obras. En 2004 una investigación hizo una propuesta tipológica para identificarlos en los acervos de los recintos religiosos y museísticos, además de proponer pautas para comprenderlos como objetos de devoción a partir de sus características materiales y formales, con apoyo de documentación histórica. (Sánchez 2004). En dicho estudio se incorporó el término de cuerpo-relicario, y se proponía la observación como único medio para identificar la osamenta, para lo cual sólo quedaba rodear la imagen para encontrarla e identificar la teca donde se depositaban las reliquias. A partir de la inspección visual realizada en varios ejemplares, quedó claro que cada relicario expone las reliquias en diferentes lugares, por lo que cada ejemplar era singular. [figura 1]

Entre los estudiosos de relicarios en ceroplástica se pensaba que cada imagen contenía únicamente las reliquias que eran visibles (Sánchez 2004), aunque se ha planteado la posibilidad de que hubiera restos óseos en el interior, pero no se tenía manera de constatarlo (Ghilardi 2012) Esta interrogante hoy día se puede resolver gracias a una propuesta resultado de una preocupación sobre la conservación y restauración de este tipo de relicario, que consiste en aplicar técnicas radiográficas para el estudio de este tipo de bienes culturales. (Montes en proceso) Si bien la radiología se ha aplicado previamente en esculturas de ceroplástica, especialmente en ceras anatómicas, no se había hecho así para esta tipología de relicario. Por primera ocasión se aplicó esta técnica en un par de relicarios 


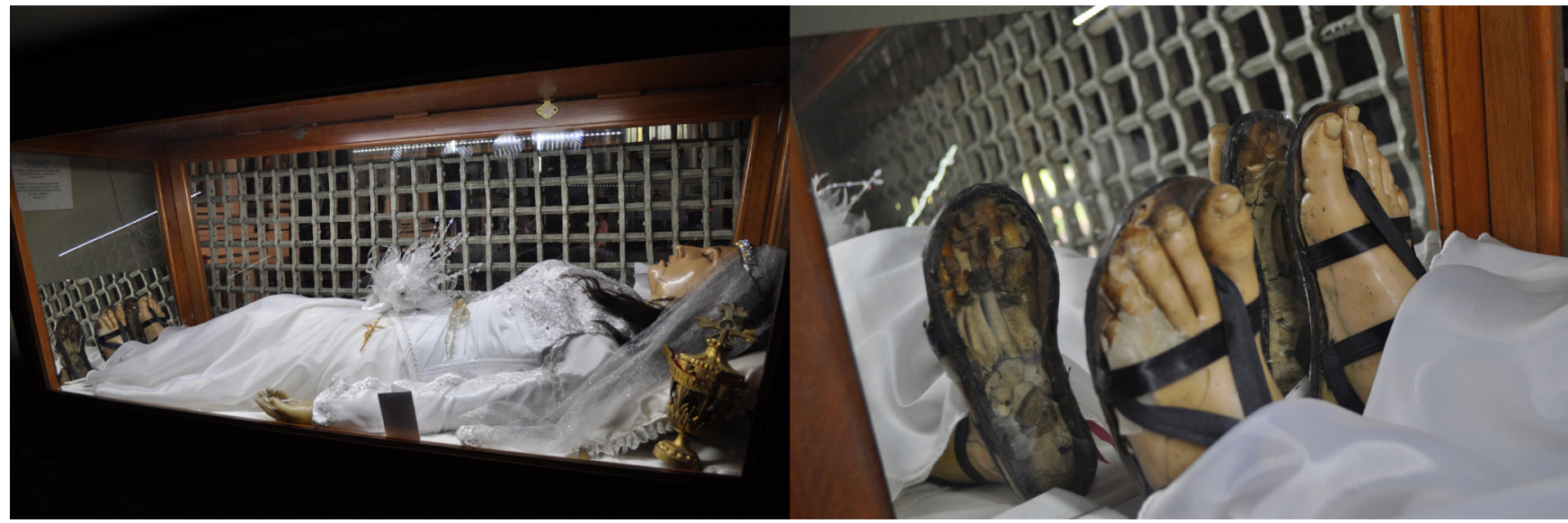

Figure 1.- La inspección visual era la única opción que se tenía para saber dónde se encontraban los restos óseos de los relicarios en ceroplástica, así que debían buscarse en los pies, brazos o cabeza. Cuerpo-relicario de santa Celeste. Templo de santa Teresa la Nueva. Ciudad de México. Fotografía Gabriela Sánchez Reyes

localizados en la Catedral de Durango, México: un cuerpo-relicario de san Plácido mártir y la cabezarelicario de ceroplástica de santa Faustina. Las placas obtenidas mostraron no sólo la estructura interna de las piezas, sino que reveló que contenía más huesos de los que se veían a simple vista (Montes, en proceso). A partir de este estudio y debido a los exitosos resultados obtenidos, se replicó esta técnica radiológica en tres obras de la Catedral Metropolitana de la Ciudad de México $^{3}$ y una más en el templo del Carmen de San Ángel, para observar la técnica de factura y los restos óseos del interior. El objetivo de este texto entonces, es mostrar los resultados de este primer muestreo donde se confirma la hipótesis planteada, siendo ésta, que cada ejemplar de cera presenta variantes en su técnica de factura y no sólo resguarda reliquias, sino que están distribuidas de forma distinta y la cantidad también varía. Lo que ha enriquecido el conocimiento sobre este tipo de obra y ha sido posible identificar vertientes en su factura así como analizar y ubicar las reliquias óseas en su interior.

\section{Aplicación de la radiología digital directa (RRD) en bienes muebles culturales}

En 1895 cuando Wilhelm Conrad Roentgen descubrió los rayos $\mathrm{X}$, nunca imaginó el alcance que tendría su descubrimiento a través de los años, extendiéndose su uso en la comunidad médica y posteriormente entre veterinarios, odontólogos, antropólogos, de la historia del arte y como herramienta de evaluación en procesos de restauración del patrimonio. Por más de 100 años se ha utilizado la película radiográfica, chasis, reveladores y fijadores para obtener imágenes radiográficas de calidad diagnóstica. Sin embargo, en la forma tradicional se requería de un cuarto oscuro para realizar el reemplazo de película radiográfica de los chasis, múltiples tamaños de éstos dependiendo de las dimensiones la obra o paciente, y luego proseguía el revelado, fijado y secado, todo ello de forma manual. Estos métodos, aunque fueron muy eficientes por muchos años, en la actualidad resultan poco prácticos y lentos desde el punto de vista logístico, sobre todo cuando se requieren realizar trabajos en campo, o cuando las obras son frágiles, y no puede trasladarse ni la obra a un laboratorio o el equipo al recinto religioso. Si bien existen equipos análogos portátiles, se requiere armar un cuarto oscuro para procesar con líquidos reveladores y fijadores. Afortunadamente, la radiología en los últimos 40 años ha dado un salto exponencial en su evolución, tanto en la forma de tomar las placas como en su revelado, y se ha automatizado este proceso haciéndolo más fácil y práctico. En la actualidad se cuentan con equipos de radiología digital directa (RDD) que recibe la radiación electromagnética, la digitaliza y convierte en imágenes radiográficas en tan sólo 4 a 8 segundos. Un equipo de estas características es sin duda una opción alterna a los equipos análogos y de radiología computarizada ( $R C$ ), teniendo como ventajas su capacidad de conocer los resultados al instante, y hace posible realizar trabajos in situ, especialmente en casos en los que los custodios del patrimonio religioso, no autorizan la salida de los bienes muebles históricos. En el caso de los equipos de radiología digital directa totalmente inalámbricos, se cuenta con dos principales tamaños de chasis digitales: $8 \times 10$ y 14 x 17 pulgadas, que optimizan los rayos $X$ que reciben y permiten obtener imágenes de extraordinaria calidad radiográfica y diagnóstica. Otra ventaja es que debido a su tamaño se pueden colocar detrás de espacios de difícil acceso como podrían ser retablos, altares, urnas, entre otros y poder obtener imágenes sin la limitante de la longitud del cable. En equipos inalámbricos esta limitante no existe ya que el chasis se puede colocar a diferentes distancias sin tener ninguna variación en la calidad de radiografía obtenida. Por otro lado existen disponibles en el mercado generadores de rayos $X$ de baterías, lo cual vuelve al sistema completamente 
inalámbrico e independiente de corriente eléctrica, lo que permite trabajar en lugares remotos, en andamios a diferente altura, en campo con antropólogos, etcétera. El software para analizar las radiografías permite realizar varias funciones de gran utilidad, como mediciones de elementos de la obra, manejar una escala de grises para ir encontrando diferentes detalles, evaluar la placa radiográfica en positivo o negativo, magnificar áreas, etc., procedimiento que en el pasado se hacía después de escanear la película radiográfica, y que en muchos casos, perdía calidad durante el proceso. En cuanto al número de radiografías que se requieren de cada obra, dependerá de las necesidades de la investigación y de la pieza a evaluar.

El formato de las imágenes radiográficas ya sea en el ámbito médico como para bienes patrimoniales, se obtiene en el sistema de comunicación de imágenes digitales DICOM por sus siglas en inglés, y entran en un almacenamiento de imágenes PACS, para ser vistas y analizadas en cualquier parte del mundo. Por otro lado, el manejo, evaluación y movilización rápida de las radiografías también es en formato JPG, por lo que pueden almacenarse en medios ópticos o magnéticos (CD, DVD, USB) o en la nube virtual. En la actualidad incluso se habla ya de radiología de alta definición (HDR), lo que pone de manifiesto la evolución que ha tenido desde sus orígenes, hace más de 120 años. El estudio radiográfico in situ aplicado a bienes culturales aporta gran cantidad de información útil sobre sus sistemas constructivos, el estado de conservación y deterioros que de otra forma pueden ser imperceptibles a simple vista. Tiene la ventaja de proporcionar un análisis global, sin duda una cualidad es la portabilidad del equipo con resultados no invasivos ni destructivos. [figura 2]

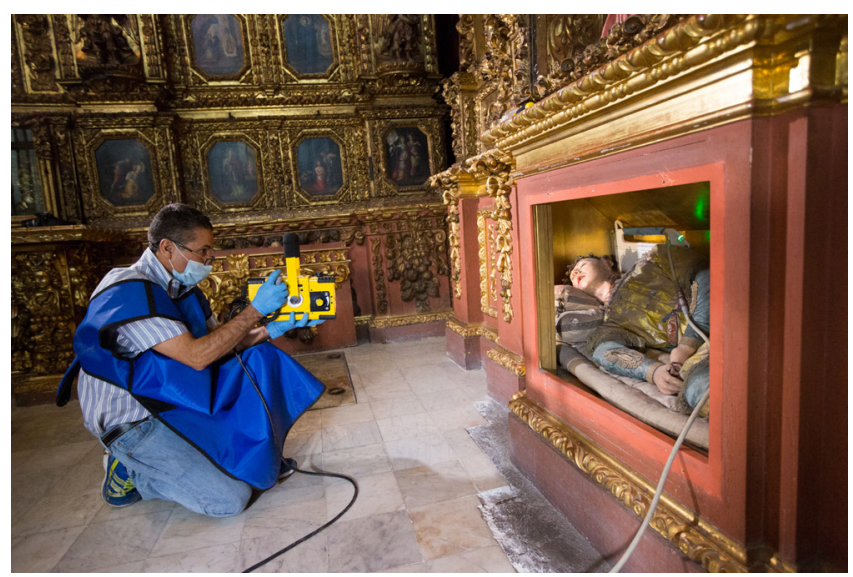

Figure 2.- Toma radiográfica in situ de un relicario donde se observa al radiólogo, el generador de rayos $\mathrm{X}$ y uso del mandil de plomo para protección de radiación; el chasis digital se aprecia por detrás del cuerpo-relicario. Es importante ver que la pieza no fue sustraída de la urna para su evaluación radiográfica. Técnica radiográfica $60 \mathrm{kv}$. mAs 0.12 . Distancia $1 \mathrm{~m}$. Generador marca mini $X$ ray. $80 \mathrm{kv} 20 \mathrm{mAs}$. Chasis digital marca cuattro de cesio. Fotografía de Javier Otaola. Radiología José Luis Velázquez.
Quizá la aplicación más conocida de la radiología en bienes muebles sea en pinturas de caballete $y$ escultura policromada, aunque también se ha utilizado prácticamente en cualquier material, como cerámica, metales, textiles y papel, por mencionar algunos. En el ámbito del estudio de los relicarios de otras tipologías, se han realizado algunos estudios de esculturas policromadas, como bustos-relicario (Valverde 2012) y brazos-relicario, ${ }^{4}$ o bien, en ejemplares de orfebrería. Una institución como el Royal Institute for Cultural Heritage (KIK-IRPA) fundado por Paul Coremans, al tener como vocación analizar científicamente las obras de arte, comenzó a utilizar la radiología en objetos tan variados como cerámica, vidrio, papel o urnas (châsses) con reliquias, sin embargo aún no han incluido en su muestreo obras en ceroplástica como esta tipología de relicario. ${ }^{5}$ Esta técnica ha demostrado su utilidad para el estudio de obras ceroplástica a nivel internacional, sobre todo para modelos anatómicos de cera y obras artísticas, por lo que es un campo abierto a la investigación (Gramtrop 2015).

Para el caso de México el estudio de la radiología de bienes culturales inició en 1957 cuando Abelardo Carrillo y Gariel analizó la escultura del Cristo de Mexicalzingo, pero fue hacia el año 2000 que se difundieron trabajos de escultura ligera (Amador 2002) en muchos casos con aparatos analógicos, lo que significaba el traslado de la pieza hasta las instalaciones donde se encuentra el generador de Ratos $X$. Mucho se ha avanzado en este sentido y sin duda se trata de una técnica que ya forma parte de los equipos de trabajo en universidades. Por ejemplo desde 2005 es parte de la currícula de los alumnos de restauración de la Escuela de Conservación y Restauración de Occidente (ECRO) en Guadalajara, Jalisco, por lo que incluso publicó un Manual de Radiología aplicada al estudio de bienes muebles, el primero en su género (Bautista e Insaurralde 2012). En el caso de proyectos museográficos, también se empieza a incluir como parte sustancial de la curaduría, como es el caso de la exposición Santiago un caballero con alma de maíz en el Museo Nacional del Virreinato. (Santiago 2016).

Hace apenas unos años se tomaron placas a algunas ceras anatómicas pertenecientes al Museo del Palacio de la Escuela de Medicina en la ciudad de México; con ello se descubrió que contenían huesos humanos, madera y relleno y piezas unidas con clavos y alambres, gracias a lo cual pudieron restaurarse adecuadamente (Perpetua Restauración 2012). Sin embargo, a pesar de la relevancia del estudio, los resultados no fueron publicados. [figura 3 ].

En el caso específico de los relicarios en ceroplástica, no se habían realizado nunca antes rayos $X$ con fines académicos. De ahí que el análisis radiológico puesto en práctica primero en los casos de Durango, y que se presenta a continuación, podrá ser de gran utilidad al diagnosticar estas esculturas de cera, para analizar su estructura y determinar estado de conservación. Los resultados son de gran interés para una amplia gama de especialistas que comparten el mismo objeto de estudio. 


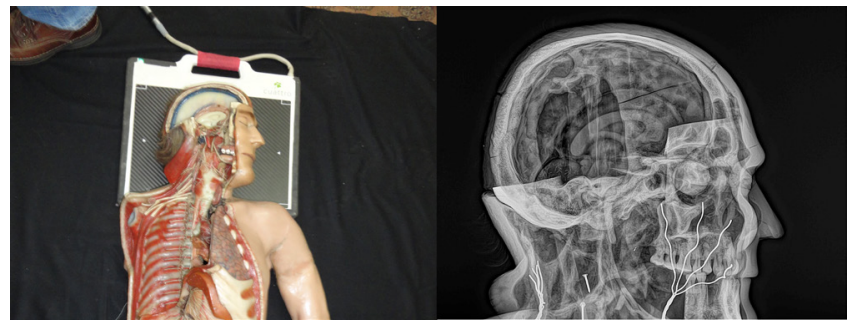

Figure 3.- Estudio radiográfico de una cera anatómica donde se encontraron restos óseos, procedimiento muy similar al de los cuerpos-relicario. Técnica radiográfica $60 \mathrm{kv}$. mAs 0.12 . Distancia $1 \mathrm{~m}$. Generador marca mini X ray. 80kv 20 mAs. Chasis digital marca cuattro de cesio. Fotografía y radiología José Luis Velázquez.

\section{La imagen radiográfica de relicarios en ceroplástica: los casos de santa Faustina y san Clemente}

Para mostrar la aplicación de la radiología para el estudio de los sistemas constructivos, se presentan dos casos de relicarios de ceroplástica, el primero es el de santa Faustina mártir, cabeza-relicario que forma parte de la colección expuesta en la Galería Episcopal de la Catedral de Durango, Dgo., (Montes en proceso); el segundo caso es San Clemente Flavio, ubicado en el templo del Carmen de San Ángel, en la Ciudad de México. Los rayos X en este tipo de obras permiten conocer si los elementos de cera son ahuecados o sólidos, si tienen armazones al interior, o identificar la presencia de distintos materiales como elementos metálicos y textiles; también es posible apreciar intervenciones anteriores, su estado de conservación general, el tipo de ensambles, así como la ubicación de las decoraciones -encajes, botones, hilos entorchados, cinturones, etcétera. El análisis se enriquece al colaborar en conjunto con especialistas de la antropología física, ya que se puede obtener información específica sobre los restos óseos del individuo, como la identificación del sexo, la edad aproximada de su muerte, el estado de conservación, la presencia de enfermedades, constatar si toda la osamenta pertenece a un mismo individuo, en caso de haber fracturas si fueron o no en vida y si los huesos se han colocado en una posición anatómica (Montes en proceso)

\section{Santa Faustina}

La actual Catedral de Durango debe su origen a la creación del obispado en 1620. El edificio actual inició su construcción en 1695 y se concluyó parcialmente en 1713, pero no fue sino hasta 1844 que la decoración interior y los altares fueron concluidos. Entre los bienes muebles que se han conservado se encuentran pinturas, mobiliario, escultura, textiles, platería y desde luego, algunos relicarios. Tal es el caso de un par de cabezas-relicario: la de santa Faustina y san Benedicto mártires [figura 4], realizados con la misma técnica de factura, aunque no se cuenta aún con información sobre su traslado y ubicación original, antes de ser parte de la Galería Episcopal. Las dos obras son una variante tipológica del cuerpo-relicario ya que presentan básicamente la misma factura: elementos de ceroplástica, restos óseos al interiory otros diversos materiales, pero sólo se representó la cabeza el mártir, cercenada, incluso sin evidenciar heridas; llevan también elementos iconográficos propios de los mártires catacumbales como el gesto in somni pacis del rostro, una corona de flores, una tablilla con su nombre en latín y se muestran dentro de urna protectora que a la vez permite admirarlas.

Esta variante al parecer no fue común, o al menos son muy pocos los ejemplares de los que se tiene noticia hasta ahora, pues apenas se conocen otros cuatro: en la localidad de

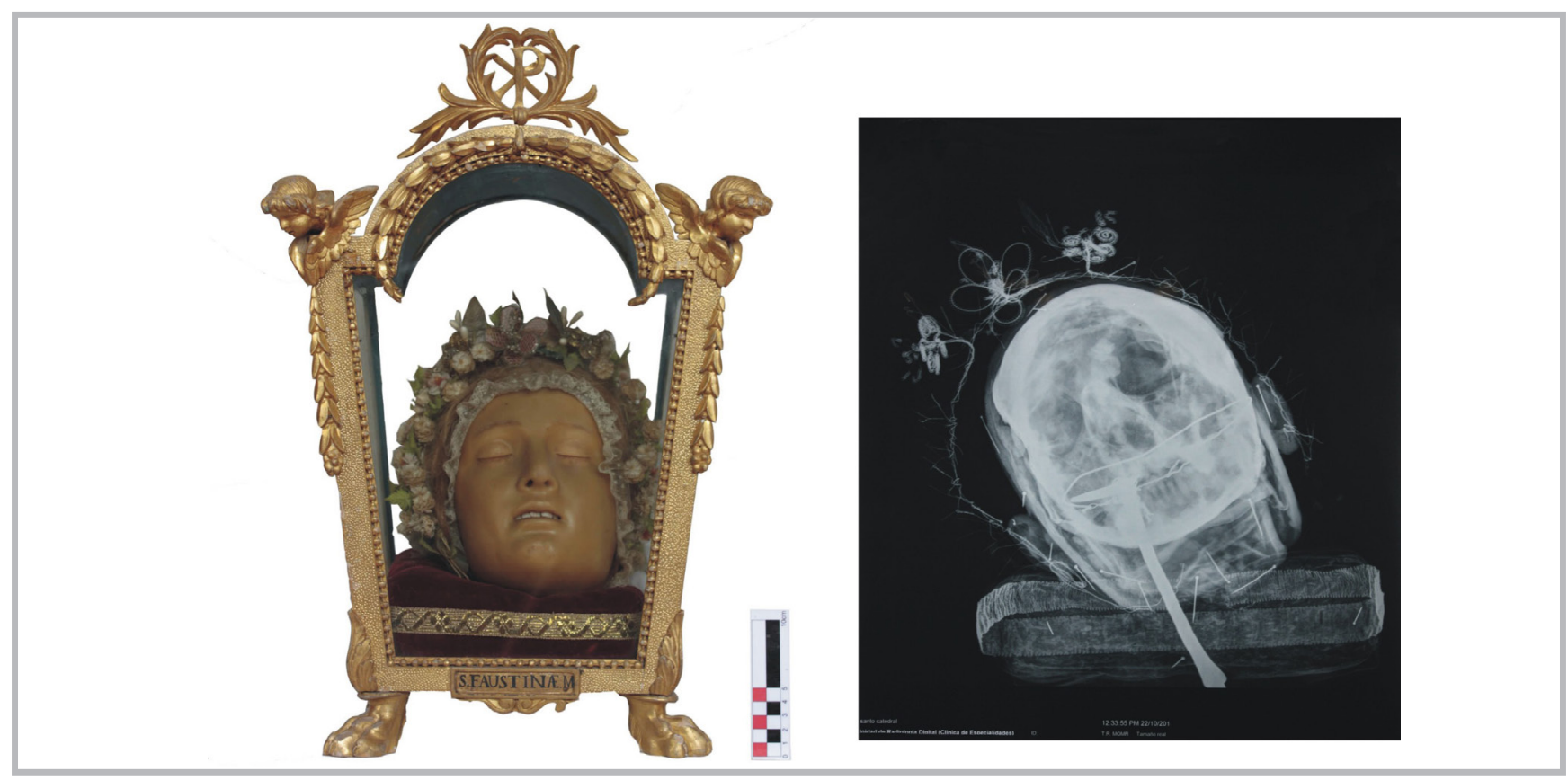

Figure 4.- (izq.) Cabeza-relicario de santa Faustina mártir en la Galería Episcopal de la Catedral de Durango, Dgo; (der.) placa radiográfica, vista frontal, donde se observa cráneo completo, elementos de cera, varilla metálica, corona de alambre e hilos metálicos del cojín. Técnica radiográfica 80 kv, 20 mAs. 1 metro distancia. Fotografía y radiología Ana Lucía Montes Marrero. 
Montalto di Castro, Italia, se encuentran los santos patronos, san Quirino y san Cándido que son sacados en procesión; en México, sólo se tenía noticia gracias a la historiadora Alicia Bazarte Martínez, de las cabezas-relicario de santa Cristina y santa Emérita del acervo de los franciscanos de Guadalupe, Zacatecas, datadas en el siglo XIX. (Bazarte) En ambos casos llama la atención que las cabezas se exponen en pares.

El estudio inicial para santa Faustina mártir, consistió en una inspección visual, para luego pasar a emplear la radiología computarizada con equipo médico portátil, por lo que la toma de placas se realizó in situ con una mínima manipulación. Debido a que sólo mide $24 \mathrm{~cm}$ x $19 \mathrm{~cm}$ x $21 \mathrm{~cm}$, fue posible sacarla de la urna para facilitar la toma de tres placas: frontal, lateral y cenital. A partir del estudio tanto visual como radiográfico se concluyó que el cráneo-reliquia es el soporte de la estructura de ceroplástica, sobre el cual se colocaron los demás elementos. Además cuenta con otros restos óseos como la mandíbula, que no está en posición anatómica, posiblemente de forma intencional, para proporcionar más soporte a la mascarilla de cera; cuenta con todas sus piezas dentales que muestran erupción del tercer molar por lo que se determinó que pertenecen a un individuo adulto mayor de 18 años [figura 5] El cráneo fue revestido con un textil embebido en cera que cubre toda la parte frontal pero deja expuesta la parte posterior del cráneo, posiblemente su función fue unir la mandíbula con el cráneo, hacer coincidir los dientes con la abertura de los labios de cera, y mejorar la adhesión de la mascarilla.

Dos hileras de dientes pueden observarse en la boca entreabierta del relicario: los inferiores corresponden a los de la mandíbula adelantada, pero los superiores están acomodados artificialmente por el interior, sujetados con una banda de textil embebido en cera, aunque no puede descartarse la posibilidad de que se trate de los propios dientes del cráneo, sacados y reacomodados según los requerimientos de la mascarilla. ${ }^{6}$

Los elementos de ceroplástica son dos, el rostro y el cuello, ambos de cera coloreada en tono encarnación. El primer elemento está hecho por molde, posiblemente tomado de un modelo vivo. El cuello se unió a la mascarilla mediante calor, luego de lo cual debió detallarse manualmente para borrar rastros de dicha unión, alisar y pulimentar la superficie mediante frotado con telas. El único toque de color se encuentra en los labios, una veladura rosada, quizá con óleo. Los postizos que posee el relicario son de cabello humano color claro. Para las cejas se hicieron incisiones verticales en las que se introdujeron los cabellos, mientras que para las pestañas se aprovecharon las ranuras de los párpados cerrados.

Una varilla de hierro proporciona estabilidad y fija la obra al fondo de la urna, aunque no se trata de un armazón interno, pues contornea al cráneo por fuera, siguiendo su curvatura. Para colocarla, se hicieron dos perforaciones al cráneo por la parte posterior. La corona está elaborada con alambre recubierto y flores de tela. La cabeza se apoya en un cojín con relleno, aparentemente de crin de caballo, que está forrado de terciopelo rojo, con un galón perimetral de hilo entorchado. Finalmente, la urna es de madera tallada y dorada, con tres vidrios que permiten observar la obra, a la vez que la protegen. La parte trasera se encuentra actualmente sin tapa o vidriera alguna, dejando expuesta la cabeza, aunque algunos restos de lacre rojo permiten sugerir que originalmente la urna estuvo sellada y en algún momento se abrió. En cuanto a estado de conservación, las radiografías mostraron que el cuello de cera, que colapsó en algún momento, se encuentra ahora dentro de la cabeza, además de la presencia de algunas fisuras en la parte posterior del cráneo, donde se hicieron los orificios para la varilla metálica.

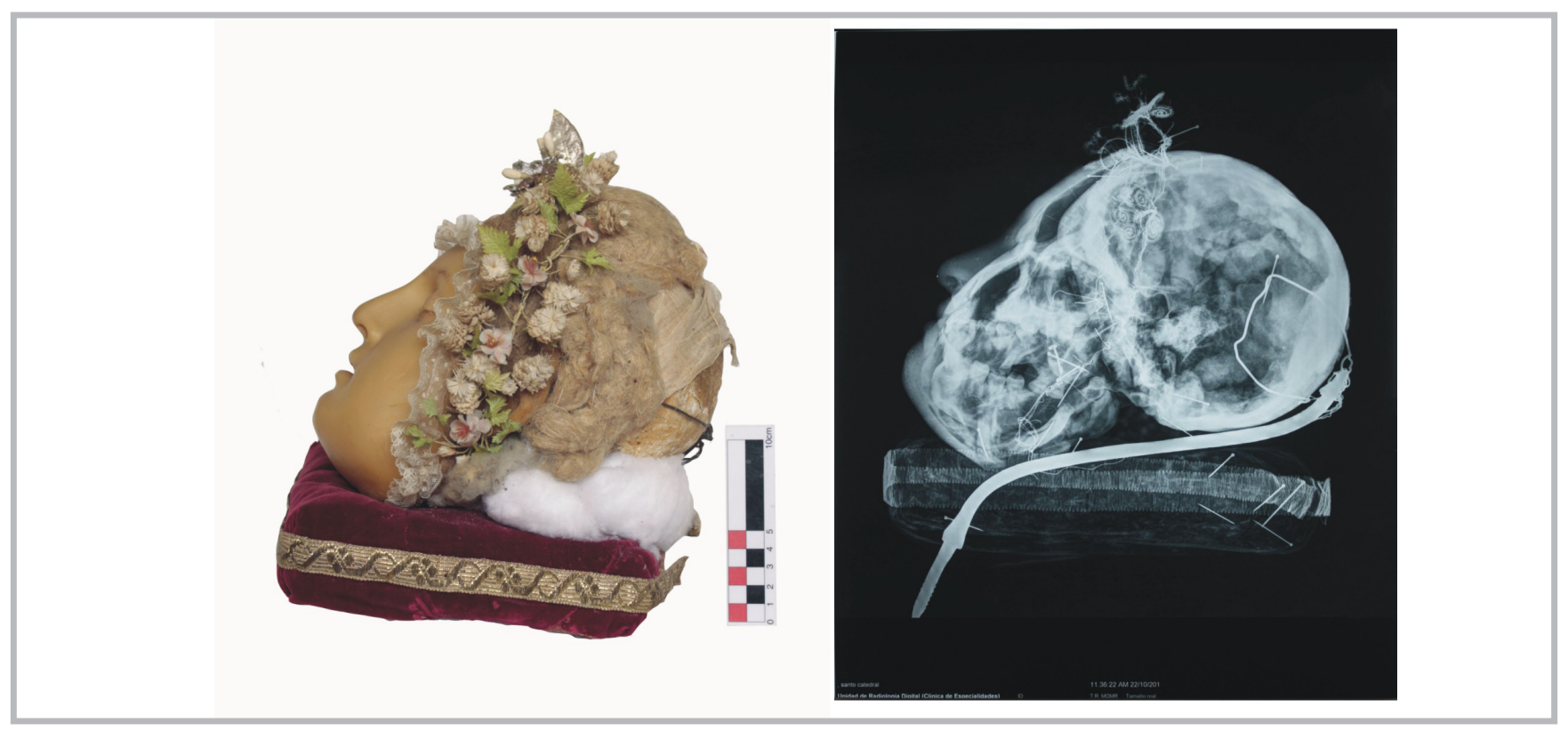

Figure 5.- Vista lateral izquierda de la cabeza-relicario, y placa radiográfica donde se observa desfase de mandíbula, cantidad de piezas dentales, y radiodensidad de la mascarilla de cera. Técnica radiográfica 80 kv, 20 mAs. 1 metro distancia. Fotografía y radiología Ana Lucía Montes Marrero. 


\section{San Clemente Flavio}

El cuerpo-relicario de san Clemente Flavio es de tamaño natural y se encuentra en el templo de el Carmen de San Ángel, en la Ciudad de México ${ }^{7}$ dentro de una urna ubicada en una mesa de altar del retablo lateral dedicado al Sagrado Corazón y realizado en el siglo XX. La Orden de los Carmelitas Descalzos llegó a la Nueva España en el año de 1585, y se fundaría la Provincia Mexicana de san Alberto, dando así inició su labor evangelizadora. Esta fundación de san Ángel es obra del fraile constructor fray Andrés de San Miguel, y la fábrica material del conjunto conventual se inició al colocarse la primera piedra en el año de 1615 y se concluyó en 1616; mientras que la iglesia se terminó en

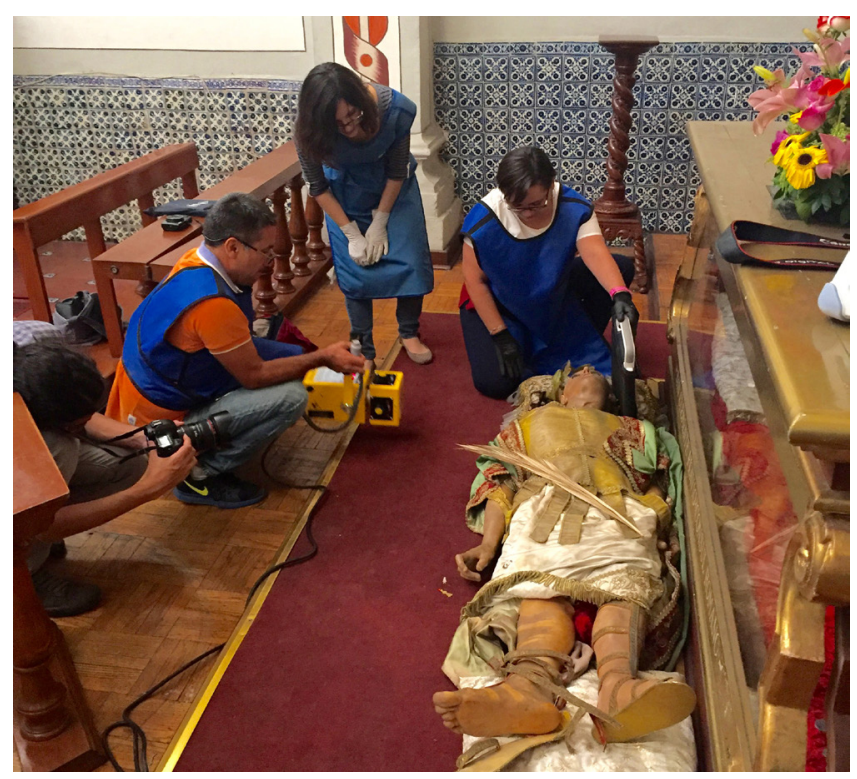

Figure 6.- Aplicación de radiología digital directa con el generador de Rayos $\mathrm{X}$ portátil en una toma de cráneo lateral. El personal porta mandiles de plomo como medida de seguridad radiológica. Fotografía José Luis Velázquez.
1626. La orden del Carmen se empeñó en tener grandes colecciones de reliquias y relicarios en sus conventos, al grado de edificar capillas-relicario en el ábside del templo, una creación totalmente novohispana, como es el caso de san Ángel, Atlixco o san Joaquín, entre otros. De igual forma se distinguieron por la creación de retablos-relicario para ostentar colecciones de reliquias de numerosos mártires y santos de la Orden como santa Teresa de Jesús y san Juan de la Cruz. (Sánchez 2004: 117-136, 153-168.) Por ello, es natural encontrar la donación de este tipo de relicarios en ceroplástica, actualmente la orden cuenta, además del cuerpo de san Clemente Flavio, con el de san Plácido en el templo del Carmen en la ciudad de Celaya, Guanajuato. Por tratarse de un mártir cuyos restos fueron extraídos de una catacumba romana, no se cuenta con una hagiografía que dé cuenta de su vida, y no ha sido posible localizar su Auténtica, es decir, el documento que especifica de qué catacumba procede, ni fecha de donación que pudiera dar razón de su origen.

Para la toma de placas del cuerpo-relicario, se empleó un equipo portátil de radiología de alta frecuencia (HF) con colimador de luz y láser para reducir la radiación secundaria. En este caso se contó con la autorización correspondiente para abrir la urna y extraer la figura para hacer un barrido completo cenital, colocando el chasis debajo de éste. [figura 6].

Un aspecto que es importante recordar es que al realizar una inspección visual del relicario, es imposible saber la cantidad y ubicación exacta de restos óseos que se encuentran al interior, y en este caso, el cuerpo de san Clemente no dejaba a la vista ninguna reliquia. [figura 7] Quedó claro entonces, que el cuerpo -tórax, muslos y brazos- están compuestos por un cuerpo de tela relleno con algodón, mientras que sólo las extremidades y la cabeza ,son de cera. Es así que, la radiología se vuelve una técnica fundamental para conocer la estructura interior de

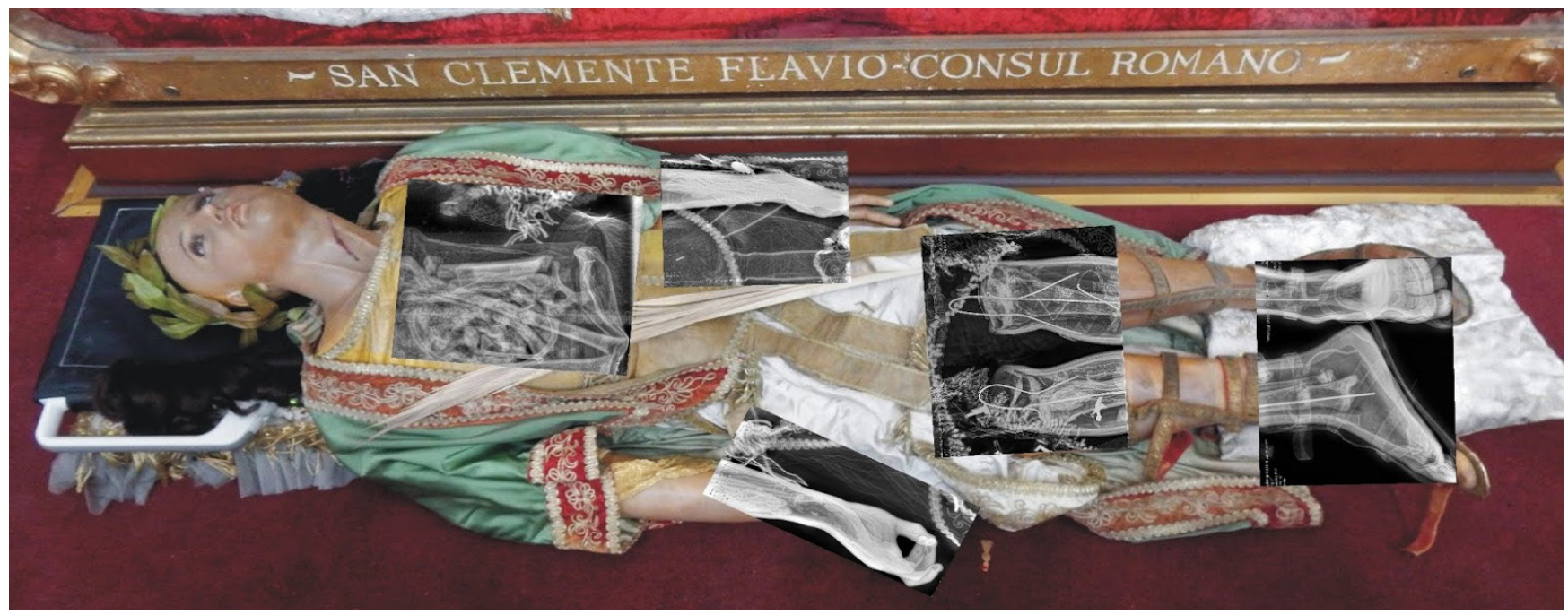

Figure 7.- Vista general del cuerpo-relicario de san Clemente Flavio, con placas radiográficas superpuestas. Técnica radiográfica $60 k v$. mAs 0.12. Distancia $80 \mathrm{~cm}$. Generador marca mini X ray. 80kv 20 mAs. Chasis digital marca cuattro de cesio. Fotografía Gabriela Sánchez Reyes y composición digital Ana Lucía Montes Marrero. Radiología José Luis Velázquez. 
la obra y su diversidad material, ya que la imagen reveló que en el área del tórax, se guardaron un conjunto de vértebras y costillas que fueron envueltas con un textil de hilo entorchado metálico, identificadas por una alta radiodensidad. En la parte central superior hay una vértebra dorsal, una rótula, una parte de vértebra cervical; al centro del lado izquierdo unos fragmentos de huesos largos, un húmero izquierdo que está roto en la parte

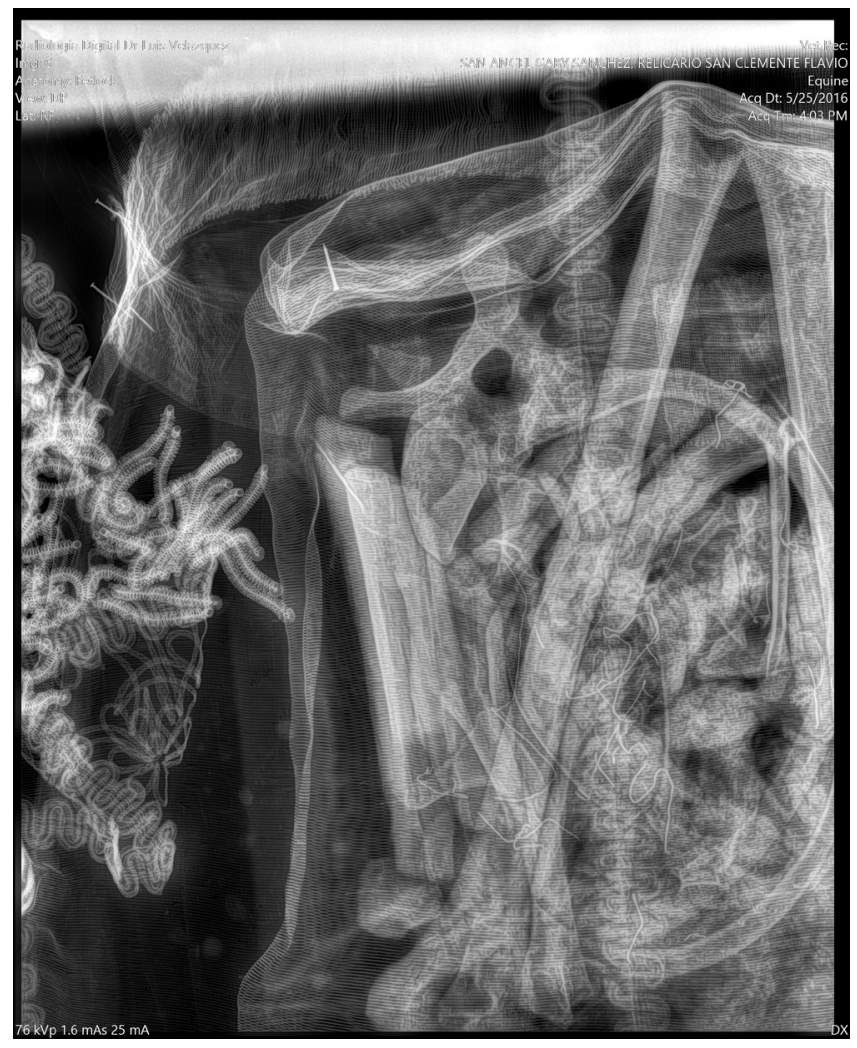

Figure 8.- Placa del tórax donde se aprecian distintos tipos de huesos como vértebras cervicales y rótulas envueltos en un textil de hilo entorchado. Técnica radiográfica $60 \mathrm{kv}$. mAs 0.12 . Distancia $1 \mathrm{~m}$. Generador marca mini X ray. $80 \mathrm{kv} 20 \mathrm{mAs}$. Chasis digital marca cuattro de cesio. Radiología José Luis Velázquez.

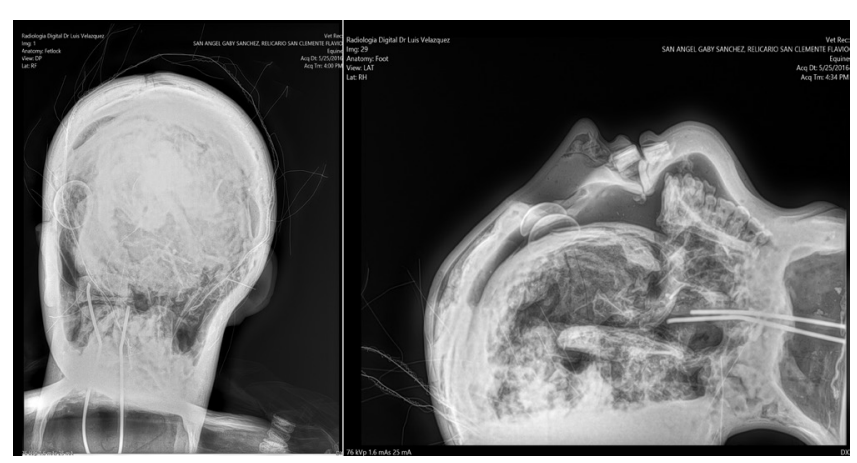

Figure 9.- (Izq) Vistas frontal que parecía indicar que no tenía restos óseos en el interior. (Der). Toma lateral donde quedó registrada la radiodensidad del cráneo, molares y alambres. Por ello se recomienda realizar tomas desde diferentes ángulos para obtener mayor información. Técnica radiográfica 60kv. mAs 0.12 . Distancia $1 \mathrm{~m}$. Generador marca mini X ray. 80kv 20 mAs. Chasis digital marca cuattro de cesio. Radiología José Luis Velázquez. superior (epífisis proximal) y en la parte inferior se aprecia la epífisis distal de radio lado no determinable. [figura 8] También se observa en la parte derecha de la placa, al menos tres costillas (una de ellas es una costilla flotante) así como un cuerpo de vértebra lumbar. La radiología también mostró que en las extremidades de cera se colocaron algunos huesos: en la cabeza, gracias a la toma lateral apareció un cráneo en posición no anatómica; [figura 9] en el caso de las piernas se registraron tibias y peroné, y en ambos antebrazos parecen contener otros huesos, aunque fragmentados. Tras la colocación de los restos óseos se añadieron los elementos de ceroplástica, realizados por vaciado en moldes -muestra de lo cual son algunas pequeñas burbujas-, y el método de unión fue a través de alambres, que por dentro recorren las piernas y antebrazos de cera. A simple vista se observan venas resaltadas en las manos, y las imágenes radiográficas mostraron lo que parecen ser alambres delgados cumpliendo esta función, lo que recuerda a los métodos de elaboración de modelos anatómicos, donde se usaban cuerdas, telas embebidas y alambre. (Montes, en proceso).

Como postizos, la cabeza lleva ojos de vidrio de media esfera, dientes superiores e inferiores realizados posiblemente con alguna pasta de carbonato de calcio a juzgar por la alta radiodensidad registrada que fueron colocados por dentro; pestañas y dos mechones gruesos de cabello que no son los originales, pues en la cabeza se aprecian manchas de adhesivo que indican que tenía otra peluca. Otro elemento importante para analizar, es la indumentaria que se compone de una túnica corta blanca con aplicaciones de hilo entorchado dorado en el borde, una coraza de textil amarillo moiré o muaré, ${ }^{8}$ y una toga o pallium verde con un borde de terciopelo rojo. Como accesorios se le colocaron una corona de alambre y una palma, símbolo de martirio.

\section{Conclusiones}

Este tipo de relicarios son obras frágiles cuya manipulación excesiva, podría derivar en deterioros debido a su complejidad estructural y material. La inspección visual como única fuente de análisis para la identificación de la técnica de factura, resulta insuficiente, pues implicaría retirar las vestimentas, los accesorios y cambiar la posición del cuerpo para acceder al interior, lo que posiblemente provocaría desensamble de elementos, quiebre de la cera, roturas en textiles, eliminación de costuras, entre otros. Debido a tal fragilidad deben estudiarse in situ, habiendo obtenido previamente el permiso correspondiente para abrir las urnas y tener acceso a la obra. La inspección visual, aunque importante, tiene sus limitantes puesto que permite únicamente tener una idea general de la estructura del cuerpo. La radiología, en cambio, permite una inspección no invasiva del interior, puesto que requiere de una mínima manipulación, por ello se recomienda contar con un equipo de rayos $X$ portátil para evitar el traslado del cuerpo-relicario. 
A partir de este primer muestreo de relicarios de ceroplástica en el que se aplicó radiología digital directa, se propone como metodología para el estudio de cada ejemplar, realizarle placas de cuerpo completo para realizar posteriormente la reconstrucción digital de la obra. Antes de iniciar la sesión de radiología es necesario contar con las medidas de las urnas así como del relicario, ya que de ello depende el tipo de chasis que se introducirá, ya sea de $8 \times 10$ pulgadas $(20.32 \times 25.4 \mathrm{~cm})$ o bien de 14 X 17 pulgadas $(35.56 \times 43.18 \mathrm{~cm})$. Para tener el registro completo del relicario, se propone emplear las siguientes vistas: latero laterales y ventrodorsales para tórax y cadera; dorso palmares y latero mediales para extremidades torácicas; dorso plantares y latero mediales para extremidades pélvicas a una distancia ideal de un metro entre la fuente de rayos $X$.

Una parte fundamental del estudio, es la interpretación de las placas radiográficas para analizar los materiales de tan variadas radiodensidades que se encuentran dentro de una misma obra, lo que permitirá dilucidar cómo fueron creadas por parte de los artistas. Para ello, se recomienda la formación de equipos de especialistas en diversas disciplinas, así como en este caso se conjuntaron los conocimientos de la restauración de bienes muebles, antropología física, radiología e historia del arte.

Debe hacerse énfasis en que cada relicario en ceroplástica a estudiar, presentará sus propias características y por consiguiente sus propios retos, por lo que la metodología de aplicación de los rayos $\mathrm{X}$ deberá modificarse según los requerimientos. Por ejemplo, el diseño de las urnas varía mucho de un ejemplar a otro, lo que implica solucionar en primer lugar su apertura para introducir los chasis, o incluso proceder al estudio con la urna cerrada, colocando los chasis por fuera. En cada caso es importante registrar en los resultados, la técnica radiográfica utilizada, precisando los valores empleados de kilovoltaje, miliamperaje, la distancia, así como las características técnicas del equipo y del chasis. En cuanto a seguridad, al momento de realizar el estudio radiológico es necesario aislar la zona en un perímetro de 3 a $5 \mathrm{~m}$ del área de trabajo, ya sea con cinta delimitadora, o bien, colocando las bancas del templo como barrera, para evitar el contacto de los visitantes con la radiación, mientras que los involucrados en el estudio deben portar mandil de plomo y dosímetros.

Existen muchos más detalles de los que el ojo puede llegar a percibir de un cuerpo-relicario, y es importante ir registrando particularidades y constantes. Ejemplos claros de lo primero los encontramos en san Clemente Flavio, donde el textil fino de hilos metálicos que protege y rodea los huesos del tórax, no hubiera sido nunca identificado de no ser por las placas radiográficas, y resulta algo distinto de la mayoría de los ejemplares en los que sólo se han encontrado textiles interiores simples e incluso burdos, como mantas de algodón. De igual forma, el hecho de encontrar el cráneo invertido, habla de las soluciones técnicas de cada artista o taller, pues es posible que haya sido una decisión consciente que facilita la factura del cuello de cera, o que brinda más soporte a la mascarilla, pero también habla de que no siempre los huesos se colocaron en posición correcta anatómicamente, y no por ello debe considerarse un desconocimiento de esta ciencia.

Conscientes de que queda un largo camino por recorrer, esta propuesta queda abierta para ampliar el muestreo y descubrir la técnica de factura de otros ejemplares mediante la radiología, una herramienta que ha probado ser tan útil en otros bienes patrimoniales. Esto permitirá formar una base de datos de los materiales comúnmente empleados, para realizar comparaciones, hallar similitudes e incluso identificar talleres o autorías. Una conclusión clara es que cada figura de cera resguarda diferente cantidad, ubicación y disposición de restos óseos, lo que bien justifica el análisis de otras obras.

La aplicación de radiología para analizar el cuerpo-relicario en ceroplástica, cambia la idea de que la función del relicario es permitir la visibilidad total de la reliquia. En este caso, la efigie que ostentaba de manera parcial su contenido, muestra a través de los rayos $x$, las reliquias antes ocultas. De igual forma, la estructura interior así como la cantidad y ubicación de los restos óseos parece que sólo era conocida por el artista que cuidadosamente las envolvió, colocó y recubrió de cera, textiles y rellenos. Frente a los fieles, y los estudiosos del arte, sólo era evidente la recreación, el simulacro del cuerpo del santo catacumbal, que yace apenas con una discreta herida. Estos relicarios comienzan ya a ser apreciados y leídos adecuadamente no como contenedores de reliquias, sino como objetos artísticos e históricos, gracias a que se está estudiando su técnica particular de factura. En la actualidad, la tecnología y en específico la radiología, permite comprender el proceso de factura de este tipo de relicario, permitiendo visualizar el interior, con toda su complejidad estructural así como la visibilidad total de los restos sagrados de los mártires catacumbales.

\section{Notas}

[1] Este término es la adaptación castellana del que se utiliza en la historiografía francesa: corps-reliquaire. Laurence Rey, "L'invencion d'une vierge martyr. les reliquiaires de sainte Philomene au XIXe siécle" en Reliques d'Europe et d'Océanie. "la mort n'en saura rien", pp. 105, 108.

[2] Agradecemos a Massimiliano Ghilardi que compartiera una copia de su ponencia inédita.

[3] Los cuerpo-relicario analizados son los de san Deodato, san Víctor Niño y santa Felícitas, que forman parte del proyecto de catalogación de la colección de relicarios de la Catedral Metropolitana de México. 
[4] Treasures of Heaven saints, relics and devotion in medieval Europe, 23 June - 9 October 2011. Exhibition, 2001. http:// www.learn.columbia.edu/treasuresofheaven/relics/ArmReliquary-of-the-Apostles.php. [consulta: 23/6/2016].

[5] http://www.kikirpa.be/EN/141/0/doc++imagerie+scient+-+Une+longue+tradition.htm.

http://www.kikirpa.be/EN/120/342/Radiographie.htm. [consulta: 23/6/2016].

[6] Agradecemos a la antropóloga física Adriana Alfaro Vega por el análisis de la osamenta.

[7] Agradecemos al padre José de Jesús Orozco OCD, responsable del Archivo Histórico de la Provincia de los Carmelitas Descalzos en México por las facilidades que dio para realizar este estudio.

[8] Término francés aplicado a textiles de seda con un patrón que forma ondulaciones.

\section{Bibliografía}

AMADOR MARRERO PABLO F., (2002). Traza española, ropaje indiano. El Cristo de Telde y la imaginería en caña de maíz. Telde: Ayuntamiento de Telde.

BALLESTRIERO ROBERTA (2013). Efigie, cadáver y cuerpo enfermo en la ceroplástica, Tesis para obtener el grado de Doctorado. Madrid: Universidad Complutense de Madrid.

BAUTISTA MARTÍNEZ JOSEFINA, MIRTA INSAURRALDE CABALLERO (coordinadoras) (2012). Manual de Radiología aplicada al estudio de bienes culturales. México: El Colegio de Michoacán- Escuela de Conservación y Restauración de Occidente.

BAZARTE MARTÍNEZ, ALICIA, "Veneración de reliquias y cuerpos de cera en los días de los fieles difuntos y todos santos", en Patrimonio cultura y turismo 16, Cuadernos, pp. 57- 68. http://www.cultura.gob.mx/turismocultural/ cuadernos/pdf16/articulo4.pdf. [ consulta: 23/6/2016].

BOUZA ÁLVAREZ JOSÉ LUIS, (1990). Religiosidad contrarreformista y cultura simbólica del barroco. Madrid: Consejo Superior de Investigaciones Científicas.

GHILARDI MASSIMILAINO (2013) "Paolino e gli altri martiri. II culto de "corpi santi" nella prima età moderna" en Il cardonal Montelpare, Atti del Convegno. Montelparo 17 giugno 2012, Archivo Diocedano San Benedetto del Trento, Quaderno perla Ricerca, 17.

GHILARDI MASSIMILAINO (2015), "Le commerce des objets de dévotion chrétiens: approches croisées (XVleXIXe siècle)" en Journée d'étude, Calenda. Ponencia inédita.
GRAMTORP DORTE, KNUD BOTFELDT, JENS GLASTRUP \& KIM PILKJ/ER SIMONSEN (2015).“Investigation and conservation of Anne Marie Carl-Nielsen's wax models" en Studies in Conservation, 60:2, 97-106, http://dx.doi.org/10 $.1179 / 2047058413$ Y.0000000111. [ consulta: 23/6/2016].

REY LAURENCE. (1999). "L'invention d'une vierge martyr. Les reliquaires de sainte Philomène au XIXe siècle" en Reliques d'Europe et d'Océanie. "la mort n'en saura rien". Paris : Musée national des Arts d'Afrique et d'Océanie.

MONTES MARRERO, ANA LUCÍA (en proceso). Radiología aplicada al estudio de relicarios en ceroplástica: técnica de factura de factura de Santa Faustina y San Plácido mártires, Catedral de Durango, México. Tesis para obtener el grado de Licenciatura en Restauración de Bienes Muebles, Escuela de Conservación y Restauración de Occidente.

PERPETUA RESTAURACIÓN (2012). "Informe de restauración". Inédito.

SÁNCHEZ REYES GABRIELA (en proceso). Reliquias $y$ relicarios en México.

SÁNCHEZ REYES GABRIELA (2004). Relicarios novohispanos a través de una muestra de los siglos XVI al XVIII. México: Tesis para obtener el grado de Maestra en Historia del Arte, Universidad Nacional Autónoma de MéxicoFacultad de Filosofía y Letras, División de Estudios de Posgrado.

Santiago un caballero con alma de maíz (2016). México: Instituto Nacional de Antropología e HistoriaCoordinación Nacional de Difusión.

VALVERDE LARROSA CONSUELO, CRISTINA GÓMEZ GONZÁLEZ, JUAN CARLOS MARTÍN GARCÍA, PILAR VIDAL MELER, MILAGROS BURÓN ÁLVAREZ (2012). “Estudios radiográficos determinantes para el conocimiento constructivo de tres esculturas policromadas realizados por el CCRBC de Castilla y León", Ge-conservación / conservação, №. 3: 152-168.

VELÁZQUEZ RAMÍREZ JOSÉ LUIS (2012). en Memoria $5^{\circ}$ Foro Académico 2012. México:, Instituto Nacional de Antropología e Historia, CONACULTA, Escuela de Conservación, Restauración y Museografía, Núm. 5, abril. https://www.revistas.inah.gob.mx/index.php/foro/ article/view/246. [ consulta: 17/5/2016]. 


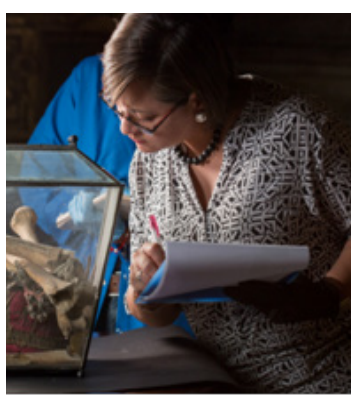

\section{Gabriela Sánchez Reyes}

gabysare@gmail.com

Instituto Nacional de Antropología e Historia

La Licenciada en Ciencias Humanas por la Universidad del Claustro de Sor Juana (1997) y Maestra en Historia del Arte con la especialidad de Arte Colonial Mexicano por la Universidad Nacional Autónoma de México (2004). Desde 2004 es investigadora de tiempo completo (Titular C) de la Coordinación Nacional de Monumentos Históricos del Instituto Nacional de Antropología e Historia. Sus líneas de investigación son la historia la urbanización y bienes inmuebles históricos en el Centro Histórico de la Ciudad de México y la cultura material de las devociones, en particular los relicarios, la medalla devocional y las medidas de imágenes. Actualmente es coordinadora del proyecto interdisciplinario para la catalogación de los relicarios de la Catedral Metropolitana de México y a la par concluye libro sobre relicarios en la Nueva España. Ha sido co-curadora de exposiciones temporales en el Museo Soumaya, Museo Franz Mayer, Museo Nacional del Virreinato y Museo del Templo Mayor.

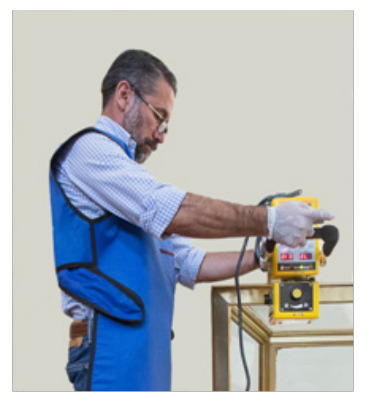

José Luis Velázquez Ramírez

jlvr@unam.mx

Universidad Nacional Autónoma de México

Obtiene el grado de Licenciado en medicina veterinaria y zootecnia en la Facultad de Medicina Veterinaria y Zootecnia por la Universidad Nacional Autónoma de México en 1990. El grado de maestro en Ciencias de la Salud y la Producción Animal por la División de Estudios de Posgrado por la misma institución en el año 2002. Es profesor de tiempo completo "Asociado C" definitivo, PRIDE "C" en la Facultad de Medicina Veterinaria y Zootecnia, imparte las cátedras de cirugía, Radiología y Clínica en equinos. Es socio de la American Assotiation of Equine Practitioners y de la Asociación Mexicana de Médicos Veterinarios Especialistas en Equinos. A partir del año 2011 ha apoyado con radiología digital directa a restauradores, historiadores del arte, escuelas de restauración y museos en bienes culturales como escultura ligera, pintura de caballete, retablos, esculturas de madera y levantamientos antropológicos. En fechas recientes es el responsable de la radiología del proyecto de catalogación de los relicarios de ceroplástica de la Catedral Metropolitana de México. 


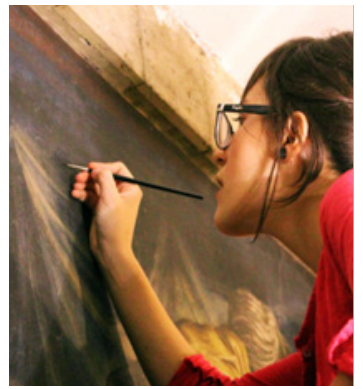

\section{Ana Lucía Montes Marrero}

lucia.m.marrero@gmail.com

Escuela de Conservación y Restauración de Occidente

Pasante de la Licenciatura en Restauración de Bienes Muebles por la Escuela de Conservación y Restauración de Occidente, Guadalajara, Jal. Participó en 2014 en el registro de bienes muebles de iglesias del Estado de Durango, proyecto del Centro Regional del Instituto Nacional de Antropología e Historia. En 2016 intervino una obra textil del Museo Nacional del Virreinato, para la exposición temporal "Santiago. Un caballero con alma de maíz". Forma parte del equipo interdisciplinario para la catalogación de los relicarios de la Catedral Metropolitana de México apoyando con el análisis del sistema constructivo de los relicarios en ceroplástica. Actualmente realiza su tesis de licenciatura titulada "Radiología aplicada en relicarios con ceroplástica: Estudio de la técnica de factura de Santa Faustina y San Plácido mártires, Catedral de Durango, México". Tiene interés particular en la conservación y restauración de textiles y de relicarios en ceroplástica y su técnica de manufactura.

\section{Artículo enviado el 15/07/2016 \\ Artículo aceptado el 07/12/2016}

